\title{
Reduced baroreceptor sensitivity in patients with chronic obstructive pulmonary disease
}

\author{
D PATAKAS, G LOURIDAS, E KAKAVELAS \\ From the University of Thessaloniki, Pulmonary Department, Thessaloniki, Greece
}

ABSTRACT Baroreceptor sensitivity, reflected by the slope of the linear regression of the electrocardiographic R-R interval on the rise of systolic blood pressure after injection of phenylephrine, was significantly lower in 27 patients with chronic obstructive pulmonary disease $(4.67 \pm 2 \cdot 67)$ than in 10 normal subjects $(12.07 \pm 3.3)$ of comparable age $(\mathrm{p}<0.001)$. In 20 patients in whom right heart catheterisation was performed, pulmonary artery pressure was inversely related to baroreflex sensitivity $(\mathrm{r}=-0.603, \mathrm{p}<0.01)$. Independent variables such as arterial $\mathrm{PO}_{2}, \mathrm{PCO}_{2}$, and mean pulmonary artery pressure were examined in order to assess their ability to predict baroreflex sensitivity. The independent variable that made the most significant contribution was mean pulmonary artery pressure. It seems that the attenuation of baroreflex response in patients with chronic obstructive pulmonary disease is caused mainly by pulmonary hypertension and partly by the central effects of hypoxia and hypercapnia.

Dysfunction of the baroreceptor reflex in man has been described in established ${ }^{12}$ and borderline hypertension, ${ }^{2} 3$ in uraemic patients, ${ }^{4}$ and in patients with heart disease..$^{5}$ There has been little study of baroreceptor function in patients with chronic obstructive pulmonary disease (COPD). ${ }^{5}$ In our study the sensitivity of the baroreceptor reflex in patients with COPD is compared with that in agematched controls.

\section{Methods}

Twenty-seven male patients with COPD and 10 normal subjects were studied. Both groups had comparable ages; mean age was $58.3 \pm 8.7$ in COPD patients and $55 \cdot 1 \pm 9 \cdot 1$ in normal subjects. No COPD patients were in congestive heart failure or acute respiratory failure on the day of the study. Patients with a history of coronary artery disease were excluded. No participants had electrocardiographic evidence of coronary artery disease using standard testing and vectorcardiography. Patients with hypertension (BP $>150 / 90)$ and patients with diabetes mellitus were also excluded. Patients with COPD were encouraged to undertake exercise according to our rehabilitation programme. The study was carried out with the full informed consent of the

Address for reprint requests: Dr D Patakas, Patriarchou Ioakim 1, Thessaloniki, Greece. subjects and was approved by the ethical committee of our hospital.

Baroreflex sensitivity was estimated by relating the increase in pulse interval (expressed as R-R interval on electrocardiography, in $\mathrm{ms}$ ) to the transient rise in systolic blood pressure in $\mathrm{mmHg}$ induced by the intravenous injection of a phenylephrine bolus. Plotting $R-R$ interval against rise in systolic blood pressure results in a linear relationship, the slope of which is a measure of baroreflex sensitivity. The steeper the slope the greater the sensitivity of the reflex. The influence of sinus arrhythmia on the analysis was minimised by excluding beats occurring during inspiration from the calculation.

All subjects were studied in the supine position after percutaneous insertion of a catheter into the brachial artery. Air flow was measured with a $N$ pneumotachograph connected to a differential $\underset{\omega}{N}$ pressure transducer (model 270, Medical Division). Electrocardiogram, blood pressure and inspiratory- 0 expiratory flow were continuously recorded on an $\stackrel{\overparen{D}}{\overparen{D}}$ eight-channel photographic recorder (DR 8, Elec- $\stackrel{\oplus}{?}$ tronics for Medicine).

Control blood pressures and R-R intervals were $\bar{O}$

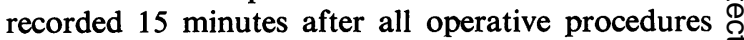
had been completed and before the evaluation of $\mathbb{\otimes}$ baroreflex function. As a control systolic arterial pressure (SAP) and control R-R interval, the mean value of the pressures of 10 successive pulse beats 
and 10 successive $R-R$ intervals was calculated. The pressor agent was injected through another catheter placed in the contralateral antecubital vein and flushed with $5 \mathrm{ml}$ of saline.

Repeated bolus injections of phenylephrine were given; usually 50 to $300 \mathrm{mg}$ were given to raise the pressure by 20 to $50 \mathrm{mmHg}$. The systolic pressures of successive arterial pulses during expiration were plotted (abscissa) against those pulse intervals which began with the next beat (ordinate). The exact dose of phenylephrine used was not important; larger doses prolonged the plotted line but did not change the slope. All our correlation coefficients were statistically significant, with probability values of less than 0.05 ( $\mathrm{r}$ usually $>0.65$ ).

Right heart catheterisation was performed in 20 patients with COPD using a no 6 Swan Ganz catheter through an antecubital vein. Pulmonary artery pressure was measured with a Statham SD-27 transducer and recorded on the Electronics for Medicine DR-8 apparatus. Cardiac catheterisation was undertaken before phenylephrine injections.

Arterial blood samples were taken with patients at rest breathing room air. The arterial samples were analysed for oxygen tension $\left(\mathrm{PaO}_{2}\right)$, carbon dioxide tension $\left(\mathrm{PaCO}_{2}\right)$, and $\mathrm{pH}$ with appropriate electrodes (Instrumentation Laboratory 213). Pulmonary function tests were performed in COPD patients and included the determination of lung volumes and capacities by the helium dilution technique using a Godart respirometer. Forced expiratory volume in one second $\left(\mathrm{FEV}_{1}\right)$ and forced vital capacity were measured in all subjects. Values are expressed as per cent of normal values obtained from Cotes. ${ }^{6}$

\section{Results}

Most of our patients had severe airway obstruction in contrast with the controls who had normal spirometry (table 1). Most COPD patients had severe hypoxia and hypercapnia (table 2). The patients had an average systolic blood pressure not significantly higher than those of control subjects. Average control R-R interval in patients with COPD

Table 1 Mean results of lung function tests in controls and subjects with COPD

\begin{tabular}{llc}
\hline & Patients with COPD & Control subjects \\
\hline n & 27 & 10 \\
Age (yr) & $58 \cdot 3 \pm 8 \cdot 7$ & $55 \cdot 1 \pm 9 \cdot 1$ \\
FVC* & $70 \cdot 5 \pm 18$ & $102 \pm 11 \cdot 4$ \\
FEV $^{*}$ & $38 \cdot 5 \pm 15 \cdot 8$ & $95 \cdot 7 \pm 11 \cdot 7$ \\
$\%^{*}$ FEV $_{1}$ & $52 \cdot 5 \pm 16 \cdot 3$ & $72 \cdot 8 \pm 4 \cdot 3$ \\
TLC* $_{\text {RV* }}$ & $121 \pm 19$ & $105 \pm 7$ \\
FRC* & $209 \pm 47$ & $113 \pm 11$ \\
\hline
\end{tabular}

*Values expressed as \% of normal. ${ }^{6}$
Table 2 Mean haemodynamic results in controls and subjects with COPD

\begin{tabular}{|c|c|c|}
\hline & Patients with COPD & Control subjects \\
\hline $\mathrm{PaO}_{2}(\mathrm{mmHg})$ & $57 \pm 13$ & $80 \cdot 2$ 士 \\
\hline $\mathrm{PaCO}_{2}(\mathrm{mmHg})$ & $50.2 \pm 11.2$ & $39 \cdot 1 \pm$ \\
\hline $\begin{array}{l}\text { Control systolic } \\
\text { arterial press. }(\mathrm{mmHg})\end{array}$ & $108 \pm 19$ & $111 \pm 18$ \\
\hline $\begin{array}{l}\text { Control R-R } \\
\text { interval (msec) }\end{array}$ & \pm 113 & \pm 108 \\
\hline$\triangle \mathbf{R}-\mathbf{R} / \triangle \mathbf{S A P}$ & 4.77 土 2.76 & $12 \cdot 07 \pm$ \\
\hline $\begin{array}{l}\text { Systolic PAP } \\
(\mathrm{mmHg})\end{array}$ & $33 \pm 14$ & - \\
\hline $\begin{array}{l}\text { Diastolic PAP } \\
(\mathrm{mmHg})\end{array}$ & $\doteq$ & 一 \\
\hline Mean PAP (mmHg) & \pm 11 & - \\
\hline
\end{tabular}

was not significantly different from those in control subjects.

The average prolongation of $\mathrm{R}-\mathrm{R}$ interval during phenylephrine-induced hypertension was 12.07 \pm $3.3 \mathrm{~ms}$ per $\mathrm{mmHg}$ in normal subjects and $4.67 \pm 2.67$ $\mathrm{ms}$ per $\mathrm{mmHg}$ in patients with COPD. Thus the baroreceptor slope in patients with COPD was significantly less than in age-matched control subjects $(p<0.001)$. Phenylephrine doses and the magnitude of pressure rise were similar in the two groups.

When the baroreceptor slope of each patient was plotted against arterial $\mathrm{PO}_{2}$ a linear correlation was obtained $(r=0.501, p<0.01)$. A linear negative correlation was also obtained by plotting arterial $\mathrm{PCO}_{2}(\mathrm{r}=-0.450, \mathrm{p}<0.02)$ and mean pulmonary artery pressure $(r=-0.603, p<0.01)$ against baroreceptor slopes.

In view of these intercorrelations most of our data were analysed with step-up multiple regression. ${ }^{7}$ This method tests for any association between a dependent and several independent variables. The results of regression of baroreceptor sensitivity on $\mathrm{PaO}_{2}, \mathrm{PaCO}_{2}$, and mean pulmonary artery pressure are presented in table 3 . The independent variable that made the most statistically significant contribution in all regression models was mean pulmonary arterial pressure.

Table 3 Linear regression models for prediction of baroreceptor sensitivity. $\left(y=b o+b_{1} x_{1}+b_{2} x_{2}+\right.$ $\left.b_{3} x_{3}\right)$

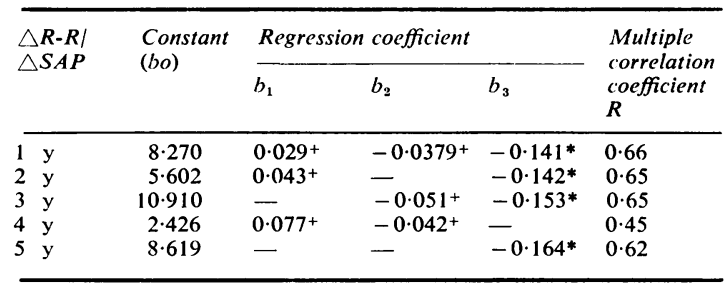

$*^{*} \mathrm{p}<0.01,+\mathrm{NS}$.

$\mathrm{x}_{1}=\mathbf{P a O}_{2}, \mathrm{x}_{2}=\mathrm{PaCO}_{2}, \mathrm{x}_{3}=\mathbf{\text { PAm }}$.

$b_{1}, b_{2}, b_{3}$ regression coefficients for $\mathrm{PaO}_{3}, \mathrm{PaCO}_{3}, \mathrm{PAm}$. 


\section{Discussion}

The results of our study indicate that patients with COPD have reduced responsiveness of the baroreceptor reflex to transient rise of blood pressure as assessed by the prolongation of the $R-R$ interval.

The method used in this study was developed by Smith et al. ${ }^{8}$ In the original method, angiotensin was used as the pressor agent, but because of the direct cardiac action of this drug $^{9}$ and the late tachycardia, which probably results from central stimulation of the sympathetic pathway, ${ }^{10}$ we decided to substitute phenylephrine. The bradycardia produced after phenylephrine injection is reflex in nature since a direct effect of the drug on the heart has been excluded. ${ }^{11} 12$

The sensitivity of the heart rate-blood pressure reflex depends on the inter-relation of autonomic nervous activity affecting the heart and it falls with a decline in vagal tone. ${ }^{1314}$ Comparison of subjects' resting heart rates can be used for detection of gross variations in autonomic tone. ${ }^{2}$ We did not find any statistically significant difference in control heart rate between our control subjects and patients with COPD to explain the attenuation of baroreflex sensitivity in patients.

Since age $^{2}$ can affect baroreceptor sensitivity, normal subjects at ages comparable to those of patients with COPD were chosen as controls in our study. In spite of the observations that bed rest and physical activity do not appear to alter baroreceptor responsiveness, care has been taken to ensure that our patients avoided excessive bed rest and immobilisation. ${ }^{17}$

There is some evidence that receptors in the aortic arch area are of greater importance than those in the carotid sinus in the reflex regulation of the heart. ${ }^{15}$ The baroreceptors lie within the arterial wall and they respond to deformation brought about by a change in transmural pressure. If the arterial wall is stiffer than normal it may be that the receptors will be splinted and protected to some extent from the arterial pressure and will respond to a given pressure rise with a reduced afferent nerve activity. ${ }^{16}$ Most of our patients were old but we cannot see any reason for them to have more severe aortic degeneration than the age-matched control subjects since blood pressure was similar in both groups.

Eckberg et alli studying patients with heart disease, found a linear regression relating R-R interval to systolic pressure with a mean slope of $4 \cdot 4$ $\mathrm{ms} / \mathrm{mmHg}$ and concluded that the baroreceptor abnormality reflected a profound abnormality in parasympathetic cardiovascular regulation in heart disease. Heart disease-induced changes in baroreceptor function could be important in the baroreceptor abnormality in some of our patients with COPD. According to our analysis mean pulmonary arterial pressure is the independent variable that makes the most significant contribution in attenuation of baroreflex function. Pulmonary artery pressure was elevated ( $>22 \mathrm{mmHg}$ ) in 11 patients and all of these had a diminished baroreceptor slope. Four out of nine patients with normal pulmonary artery pressure had a remarkable attenuation of baroreceptor sensitivity $(\Delta R-R / \Delta S A P \leqslant 5 \cdot 6)$. It seems that pulmonary hypertension alone cannot explain the loss of baroreceptor sensitivity in all patients.

Hyperoxic hypercapnia has been shown to produce a resetting of the threshold in normal subjects without a change of the sensitivity of the reflex. ${ }^{18}$ Patients with chronic lung disease also became hypotensive during lower body negative pressure with minimal reflex vasoconstriction of forearm vessels ${ }^{19}$ in contrast with what happens in normal subjects, where during hypoxia arterial pressure is maintained despite the sudden "haemorrhage" by reflex vasoconstriction and tachycardia. ${ }^{20}$

In our patients with COPD the attenuation of baroreceptor sensitivity was more prominent in those with lower arterial $\mathrm{Po}_{2}$ and higher arterial $\mathrm{PCO}_{2}$. We are not aware of evidence that these gaseous stimuli have any effect on the baroreceptors themselves or on the afferent fibres passing from them. Likewise, no direct action of moderate changes in $\mathrm{PCO}_{2}$ or $\mathrm{pH}$ on the firing rate of pacemaker cells in the heart would be anticipated and probably therefore there would be no change in the sensitivity of the cardiac response to extrinsic neural influences. ${ }^{21}$ By exclusion, the attenuation of the baroreflex appears to be central. The central sites might be multiple: chemical and electrical stimulation of the superficial medullary hydrogen ion $\left(\mathrm{CO}_{2}\right)$ receptors is associated with circulatory as well as respiratory effects and the rise of blood pressure seen is more prominent than tachycardia. ${ }^{22}$

In conclusion, patients with chronic obstructive pulmonary disease have a blunted baroreceptor response to pharmacologically induced blood pressure changes partly related to pulmonary hypertension and partly to hypoxia and hypercapnia. N

The role this dysfunction of the baroreceptor reflex plays in patients with COPD remains unknown. The ability to alter heart rate constitutes an extremely important mechanism by which the cardiac output $\stackrel{0}{\rightarrow}$ is adjusted. Changes in heart rate account in large 0 measure for changes in cardiac output, alteration 0 in stroke volume playing a far less important part..23 In patients with COPD the ability of stroke volume $\mathbb{\otimes}$ to rise is limited during exercise because of poor filling of the left ventricle, ${ }^{24}$ and when this limitation is combined with defective control of heart rate, it $\delta$ 
may contribute importantly to the inability to raise cardiac output appropriately, especially during exercise.

We would like to thank Professor CH Frankakis and G Ziutas for their help in the statistical analysis.

\section{References}

${ }^{1}$ Bristow JD, Honour AJ, Pickering GW, Sleight P, Smyth HS. Diminished baroreflex sensitivity in high blood pressure. Circulation 1969;39:48-54.

${ }^{2}$ Gribbin B, Pickering TG, Sleight P, Peto R. Effect of age and high blood pressure on baroreflex sensitivity in man. Circ Res 1971;29:424-31.

${ }^{3}$ Takeshita A, Tanaka S, Kuroiwa A, Nakamura M. Reduced baroreceptor sensitivity in borderline hypertension. Circulation 1975;51:738-42.

${ }^{4}$ Lazarus JH, Hampers CL, Lowrie EG, Merrill JP. Baroreceptor activity in normotensive and hypertensive uremic patients. Circulation 1973;47:1015-21.

${ }^{5}$ Eckberg DL, Drabinsky M, Braunwald E. Defective cardiac parasympathetic control in patients with heart disease. New Engl J Med 1971 ;285:877-83.

${ }^{6}$ Cotes JE. Lung function. Oxford: Blackwell, 1965.

${ }^{7}$ Scheffe H. The analysis of variance. New York: John Wiley and Son, 1967.

${ }^{8}$ Smyth HS, Sleight P, Pickering GW. Reflex regulation of arterial pressure during sleep in man: a quantitative method of assessing baroreflex sensitivity. Circ Res 1969;24:109-21.

${ }^{9}$ Koch-Weser J. Nature of the inotropic action of angiotension on ventricular myocardium. Circ Res 1965; 16:230-7.

${ }^{10}$ Scroop CC, Whelan RF. A central vasomotor action of angiotension in man. Clin Sci 1966;30:79-90.

11 Varma S, Johnsen SD, Sherman DE, Youmans WB. Mechanisms of inhibition of heart rate by phenylephrine. Circ Res 1960;8:1182-6.

${ }^{12}$ Keys A, Violante A. Cardio-circulatory effects in man of neo-synephrin. J Clin Invest 1942;21:1-12.

${ }^{13}$ Bristow JD, Brown EB, Cunningham DJC et al. Effect of bicycling on the baroreflex regulation of pulse interval. Circ Res 1971;28:582-92.

${ }^{14}$ Smyth HS, Sleight P, Pickering GW. Reflex regulation of arterial pressure during sleep in man. Circ Res 1969;24: 109-21.

${ }^{15}$ Vatner SF, Franklin D, Van Citter RL, Braunwald E. Effects of carotid sinus nerve stimulation on blood flow distribution in conscious dogs at rest and during exercise. Circ Res 1970;27:495-503.

${ }_{16}$ Aars H. Relationship between aortic diameter and aortic baroreceptor activity in normal and hypertensive rabbits. Acta Physiol Scand 1969;75:406-14.

${ }^{17}$ Eckberg DL, Drabinsky M, Braunwald E. Defective cardiac parasympathetic control in patients with heart disease. New Engl J Med 1971;285:877-83.

${ }^{18}$ Bristow JD, Brown FB, Cunningham DJC, Goode RC, Howson MG, Sleight $P$. The influence of ventilation, carbon dioxide and hypoxia on the baroreceptor reflex in man. $J$ Physiol (Lond) 1971;216:281-301.

${ }^{19}$ Heistad DD, Abboud FM, Mark AL, Schmid PC. Impaired reflex vasoconstriction in chronic hypoxemic patients. J Clin Invest 1972;51:331-44.

${ }^{20}$ Heistad DD, Wheeler RC. Effect of acute hypoxia on vascular responsiveness in man. I. Responsiveness to lower body negative pressure and ice on the forehead, II. Responses to norepinephrine and angiotension, III. Effect of hypoxia and hypercapnia. J Clin Invest 1970; 49:1252-87.

${ }^{21}$ Vaughan Williams EM. The individual effects of $\mathrm{Co}_{2}$ bicarbonate and $\mathrm{pH}$ on the electrical and mechanical activity of isolated rabbit auricles. $J$ Physiol 1955;129: 90-110.

${ }^{22}$ Loescheke HH, De Lattre J, Schläfke ME, Trouth CO. Effects on respiration and circulation of electrically stimulating the ventral surfaces of medulla oblongata. Respir Physiol 1970;10:184-97.

${ }^{23}$ Franklin DL, Ellis RM, Rushmer RF. Aortic blood flow in dogs during treadmill exercise. J Appl Physiol 1959; 14:809-12.

${ }^{24}$ Minh Vu Dinh, Lee HM, Vasquez P, Shepard JW, Bell JW. Relation of $\mathrm{Vo}_{2}$ max to cardiopulmonary function in patients with chronic obstructive lung disease. Bull Europ Physiopathol Respir 1979;15:359-75. 